amount of information which has usually, and we think appropriately, been treated of by separate authorities. The book is, in fact, a sort of encyclopædia of breadmaking, and this being the case, it is open to the faults of such works. The design or scope is too large, and the matter introduced to our notice is often too remotely relevant to the immediate wants of the reader. A definition of chemistry, a table of atomic weights, an explanation of chemical equations, atoms and molecules, are scarcely necessary in this connection. Similarly, we cannot approve of lessons upon polarisation of light, the uses of the microscope, and the camera lucida being introduced in extenso into a book specially treating of a technical subject like this. Such knowledge ought to be assumed as already possessed by the reader; and as well might the author have given instruction upon the origin and uses of decimal fractions, or led up to his subject by several preliminary volumes dealing with the whole "circle of the sciences." Certainly he lays himself open to the charge of instructing either too much or too little. He deals with abstract scientific problems lying at the root of chemistry, and with the vulgar processes of the cook and the baker; and treats with equal facility of the microscope and the flour-mill. We had rather leave the minuter criticis'n of this voluminous work to the many experts whom it concerns, and who will no doubt be ready to detect any errors into which the indefatigable and talented author may have fallen. If Mr. Jago is ever tempted to bring out a second edition, we may recommend the use of the pruning-knife, which, if judiciously and freely used, will leave a better proportioned but less bulky treatise in our hands.

\section{JOHN WRIGHTSON}

\section{OUR BOOK SHELF}

American Fournal of Mathematics, vol. viii. No. 3 . (Baltimore, July r 886.)

IN her note on "the binomial equation $x^{p}-\mathrm{I}=0$," Miss Scott gives a somewhat simpler form of the equation for quartisection than that given by Prof. Cayley (L.Math. S.Proc., vol. xi. pp. II-14), and works out the equation for quinquisection on apparently different lines from $\mathrm{Mr}$. F. S. Carey's solution (cf. Prof. Cayley, L.Math.S.Proc., vol. xii. and vol. xvi.). Mr. F. N. Cole furnishes "A Contribution to the Theory of the General Equation of the Sixth Degree," which is interesting from the historical details which he gives. He acknowledges his great indebtedness to Klein, but there is a goot deal of original work in the note. Mr. J. C. Fields gives a neat "proof of the elliptic-function addition-theorem." The piece de résistance of the number is, however, the long-looked-for notes of "Lectures on the Theory of Reciprocants," by Prof. Sylvester. These are designed as "a practical introduction to an enlarged theory of algebraical forms, and, as such, are not constructed with the rigorous adhesion to logical order which might be properly expected in a systematic treatise. The object of the lecturer was to rouse an interest in the subject, and in pursuit of this end he has not hesitated to state many results, by way of anticipation, which might, with stricter regard to method, have followed at a later point in the course." The lectures, which are ten in number, have been reported by $\mathrm{Mr}$. J. Hammond. The subject, which, it will be remembered, was fully brought before our readers by Prof. Sylvester's inaugural lecture, printed in extenso in NATURE (vol. xxxiii. pp. 222-23I), has already attracted many of our younger mathematicians, so that there is hope of the Professor's closing aspiration of creating "such a school of mathematics as might go some way at least to revive the old scientific renown of Oxford" being soon an accomplished fact.

The Non-Euclidian Geometry Vindicated: a Reply to Mr. Skey. (Transactions of Wellington Philosophical Society.)

A PAPER entitled "On the Simplest Continuous Manifoldness of Two Dimensions and of Finite Extent," by Mr. F. W. Frankland, was read before the London Mathematical Society, December 14, I876 (Proc., vol. viii. pp. 57-64), and was subsequently published in our columns (vol. xv. p. 515) This same paper, or one of similar character with identical title, appears to have given rise to a paper by Mr. Skey, which took the form of notes on Mr. Frankland's paper, and was read before the Wellington Philosophical Society on June 26, I 880 (published in the thirteenth volume of the Transactions of the New Zealand Institute). The pamphlet before us is an abridgment of a series of letters in which $\mathrm{Mr}$. Frankland convincingly replies seriatim to the main points raised by Mr. Skey, and maintains his former ground by additional arguments.

\section{LETTERS TO THE EDITOR}

[The Editor does not hold himself responsible for opinions expressed by his correspondents. Neither can he undertake to return, or to correspond with the writers of, rejeited manuscripts. No notice is taken of anonymous communications.

[The Editor urgently requests correspondents to keep their letters as short as possible. The pressure on his space is so great that it is impossible otherveise to insure the appearance even of communications containing interesting and novel facts.]

\section{The Sense of Smell}

I kNOw a person who has never been conscious of any odour from a bed of mignonette, and I know another person who has never been conscious of any odour from a bean-field. Both of these persons have the sense of smell acute and discriminating as regards other odours.

I know persons who cannot discover a difference between certain odours which are very different to ordinary persons. Then there are persons who are sickened by certain odours which usually give pleasure. A considerable number of persons seem to be altogether destitute of the sense of smell ; and on the other hand there are a few who have the sense very strongly developed.

I am at present investigating peculiarities of this sense, and I shall feel obliged to any one who will furnish me with illustrations or examples-whatever their character may be-with such fullness and precision as will enable me to use them in a scientific inquiry. ARTHUR MitCHELI

34, Drummond Place, Edinburgh, September 24

\section{Palæolithic Implements in Cambridgeshire}

FEW Palæolithic implements have, I believe, been discovered in Cambridgeshire, although they are abundant in the gravels of the neighbouring counties of Suffolk and Essex. It may therefore interest your readers to learn that three implements have lately been found near Kennet, on the surface of a field not far from the high-roaa from Newmarket to Thetford. Two of the implements are kite-shaped. One, of lustrous black flint, is acutely pointed, with sharp cutting edges, and has a part of the original crust of the flint left on one of the faces, which is less convex than the other. It has lost a portion of the buttend, but is otherwise perfect. The third is a sharp-rimmed ovate implement, the surface of which is stained a deep ochreous colour. Portions of the original crust remain on the faces and base.

Two other implements of the pointed type have been found on the surface near Kennet, but are not in my possession.

In the winter of $1884-85$ several implements and flakes were 